\title{
A Compact Wideband Circularly Polarized Microstrip Slot Antenna with Parasitic Elements
}

\author{
Chenhui Xia, ${ }^{1}$ Shuo Diao, ${ }^{2}$ Wenting Yin $\mathbb{D},{ }^{3}$ Zhifang Huang, ${ }^{4}$ Lei Wang $\mathbb{D},{ }^{2}$ \\ and Dengyun Lei $\mathbb{D i D}^{2}$ \\ ${ }^{1}$ The 58th Research Institute of China Electronics Technology Group Corporation, Wuxi, China \\ ${ }^{2}$ China Electronic Product Reliability and Environmental Testing Research Institute, CEPREI, Guangzhou, China \\ ${ }^{3}$ Empyrean Technology Co., Ltd, Beijing, China \\ ${ }^{4}$ School of Automation, Guangdong University of Technology, Guangzhou, China \\ Correspondence should be addressed to Lei Wang; leiwang@ceprei.com and Dengyun Lei; leidengyun@163.com
}

Received 27 July 2021; Revised 22 August 2021; Accepted 31 August 2021; Published 28 September 2021

Academic Editor: Paolo Burghignoli

Copyright ( $\odot 2021$ Chenhui Xia et al. This is an open access article distributed under the Creative Commons Attribution License, which permits unrestricted use, distribution, and reproduction in any medium, provided the original work is properly cited.

A compact wideband circularly polarized (CP) microstrip slot antenna (MSA) with parasitic elements is designed in this letter. The CP MSA comprises a square-loop sequential-phase (SP) feeding configuration, four rotated rectangular patches, and four $L$ shaped slots embedded in the ground plane. The square-loop SP feeding structure comprises a square loop and an arc-shaped strip, which could provide a $270^{\circ}$ phase difference. Four rotated rectangular patches are placed at the edge of the square-loop feeding configuration using a capacitively tightly coupled feeding method to stimulate the CP resonant mode. After selecting these elements and tuning proper dimensions, the broad operating bandwidths of $4.38-5.25 \mathrm{GHz}(18 \%)$ for $\left|S_{11}\right|<-10 \mathrm{~dB}$ and 4.65-5.31 GHz (13.2\%) for $\mathrm{AR}<3 \mathrm{~dB}$ could be realized. Hence, the designed CP MSA has a potential application value in wireless communication.

\section{Introduction}

Because of the obvious merits, antenna arrays have been massively used in wireless communication systems. Compared with single-antenna units, antenna arrays have excellent characteristics in terms of wide bandwidth, high gain, and stable radiation patterns $[1,2]$. Conversely, circular polarization (CP) antennas have obtained considerable attention in satellite and mobile communication $[3,4]$ because of their outstanding features of overcoming polarization misalignment and reducing multipath interference with respect to linear-polarization antennas. Thus, CP antenna arrays (CPAAs) have naturally been significantly studied because of their combination of the advantages of the two structures.

Thus far, several effective methods have been proposed for designing the CPAAs [5-10]. To compare and analyze these structures, the feeder network is essential in antenna array design. For example, two $T$-junction power dividers are joined as a sequential phase (SP) shifting feeding network in [5], two phase-shifted swaps and a $1: 8$ power divider are combined as stripline feeding network in [6], and Wilkinson power combiners and delay lines are used as a beamforming network in [7]. Among these feeding strategies, the SP feeding network is one of the potential candidates in the design of antenna arrays, which could excite a stable and SP difference to the port of the feedline. When the SP feeding network is introduced into the design of $2 \times 2$ CPAAs, the impedance bandwidth (IBW) and axial ratio (AR) bandwidth of CPAAs could be improved simultaneously. The SP feeding network could be categorized as follows: a series-parallel feeding structure [11, 12], aperturecoupled structure [9], coplanar waveguide-fed structure [13], and a square-loop rotated feed-network structure [14-22].

Additionally, based on the SP feed-network, the stacked technology is effective in CPAAs [21-25]. Round [21] and rectangular [22] patches as parasitic elements are stacked 
above the SP rotated feeding structure, which realize $6 \%$ and $28.1 \%$ of CP bandwidth, respectively. Although the stacked structure enhances the $\mathrm{CP}$ bandwidth, the profile of CPAAs is too high to meet the requirements of system integration.

This study develops a new scheme of the CP microstrip slot antenna (MSA) with $2 \times 2$ array and low-profile characteristics. The proposed CP MSA comprises a square-loop SP feed-network, four rotated rectangular patches, and four $L$-shaped slots embedded in the ground plane. The squareloop SP feed-network is composed of a square loop and an arc-shaped strip, which could provide a $270^{\circ}$ phase difference. Four rotated rectangular patches are placed at the edge of the square-loop feeding configuration using a capacitively tightly coupled feeding method to stimulate a CP resonant mode. After selecting these elements and tuning proper dimensions, broad operating bandwidths of $4.38-5.25 \mathrm{GHz}$ (18\%) for $\left|\mathrm{S}_{11}\right|<-10 \mathrm{~dB}$ and $4.65-5.31 \mathrm{GHz}(13.2 \%)$ for $\mathrm{AR}<3 \mathrm{~dB}$ could be realized.

\section{Antenna Design}

2.1. Antenna Configuration. Figure 1 shows the entire structure and detailed geometry of the proposed CP MSA with SP feeding characteristics. The proposed CP MSA comprised four rectangular patches with dimensions $(L 1 \times L 2$ and $L 3 \times L 4)$, four $L$-shaped slots with dimensions $(D 4 \times D 5 \times D 6)$, a square-loop SP feed-network, which includes a square-loop with inner and outer side length $(D 2 \times D 3)$, and an arc-shaped strip with different radius $(R 1 \times R 2)$. The square-loop feeding structure and rectangular patches are printed at the top of a substrate (Rogers 5880, $\varepsilon r_{1}=2.2, H 1=1.524 \mathrm{~mm}$, and $\left.\tan \delta=0.0009\right)$, whereas the $L$ slots are etched at the bottom of the substrate. A high frequency full-wave simulator is used to tune the dimensions of the proposed CP MSA, and the optimized sizes are listed as follows: $L=55.4 \mathrm{~mm}, W=55.4 \mathrm{~mm}, L 1=18 \mathrm{~mm}, L 2=19.2$ $\mathrm{mm}, L 3=3 \mathrm{~mm}, L 4=2.9 \mathrm{~mm}, D 1=2.6 \mathrm{~mm}, D 2=9.2 \mathrm{~mm}$, $D 3=13.2 \mathrm{~mm}, D 4=19.9 \mathrm{~mm}, D 5=25.1 \mathrm{~mm}, D 6=2.6 \mathrm{~mm}$, $R 1=1.6 \mathrm{~mm}, R 2=3.8 \mathrm{~mm}$, and $H 1=1.524 \mathrm{~mm}$.

2.2. Antenna Mechanism. To reveal the operated mechanism of the proposed CP MSA, Figure 2(a) shows four evolutionary models (Ant. I to Ant. IV). The models depict a stepby-step design process, and for comparison, Figures 2(b) and 2 (c) show the corresponding $\left|S_{11}\right|$ and AR values. Note that the square-loop SP structure could excite the fundamental mode $\left(\mathrm{TM}_{11}\right)$, and the corresponding resonance-frequency point $\left(f_{11}\right)$ can be tuned by using the average circumference of the square loop, and the formula is as follows [17]:

$$
f_{11}=\frac{c}{2(D 2+D 3)} \times\left(\frac{1+\varepsilon_{r}}{2 \varepsilon_{r}}\right)^{1 / 2},
$$

where $\varepsilon_{r}$ represents the dielectric constant of the substrate, $c$ represents the speed of light, and D2 and D3 represent the square-loop side-lengths. When the length of the arc-shaped strip is a quarter of the waveguide wavelength, the $90^{\circ}$ phase difference could be obtained, which is a necessary condition for exciting $\mathrm{CP}$ resonant modes. Instead of using the

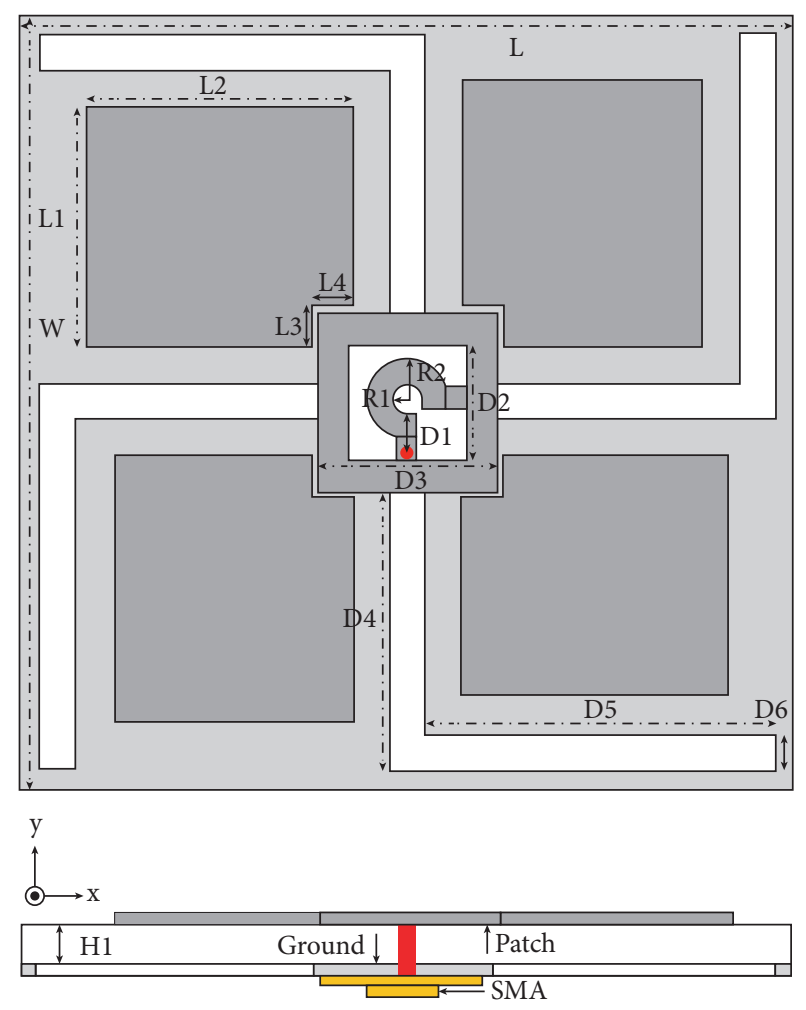

Figure 1: Geometry of the proposed antenna.

traditional placement method that places four rectangular/ square patches at the edge of the square loop $[16,17,22]$, we chose to place four rotated rectangular patches at the corners of the square loop (Ant. I) through proximity coupling. As shown in Figure 2, Ant. I with four rotated rectangular patches has two AR resonant points, with AR values being less than $3 \mathrm{~dB}$. This is because the square-loop SP structure could provide a stable continuous phase $\left(0^{\circ}, 90^{\circ}, 180^{\circ}\right.$, and $\left.270^{\circ}\right)$. When four $L$-shaped strips are separately connected with the square-loop, Ant. I has poor return-loss and AR values. To improve the $\mathrm{CP}$ bandwidth of Ant. II, the $L$ shaped strips and rectangular patches are introduced into Ant. III. The $3 \mathrm{~dB}$ ARBW and $-10 \mathrm{~dB}$ IBW of Ant. III could be improved. However, the CP performance of Ant. III is not as good as that of Ant. I, meaning that the four L-shaped strips do not increase the bandwidth. Furthermore, when the $L$-shaped strip as a parasitic slot is etched into the ground plane, the ARBW and IBW of Ant. IV could be increased. Regarding performance improvement, the introduction of L-shaped slots could generate a new current flow path and extend the previous current path, which deviates the AR resonance points. Finally, the proposed antenna could realize a wide $-10 \mathrm{~dB}$ IBW of $19.8 \%(5.64,5.08-6.2 \mathrm{GHz})$ and a $3 \mathrm{~dB}$ ARBW of $17.5 \%(5.5,5.02-5.98 \mathrm{GHz})$. Furthermore, Table 1 presents a comparison with previously published CP antennas to demonstrate our design's superior performance. From the table, although the CPBW and peak gain of the proposed antenna is not as good as some referenced antennas in Table 1, the proposed antenna features a new design and low profile, which is the greatest contribution of the proposed antenna. 

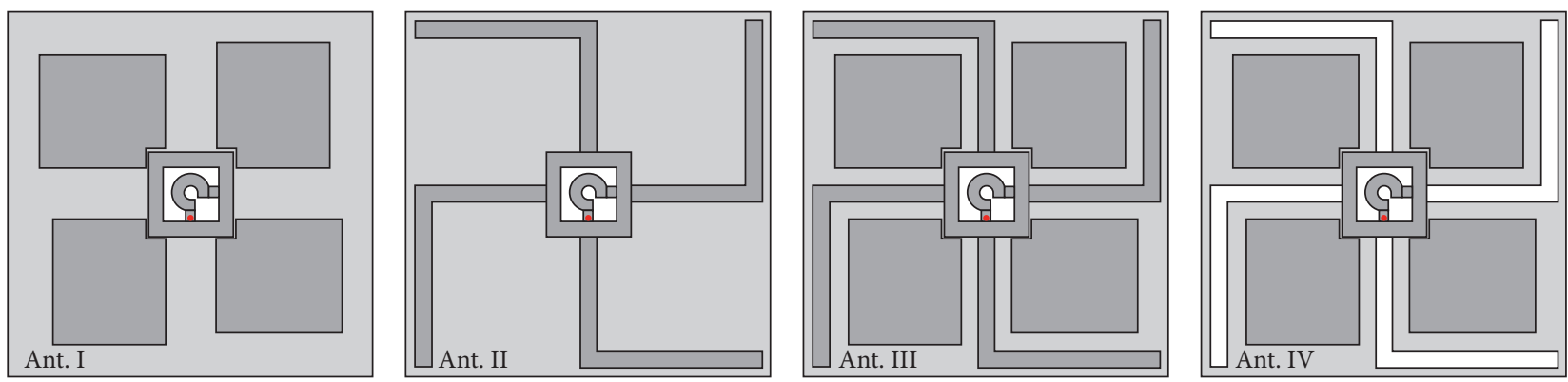

(a)

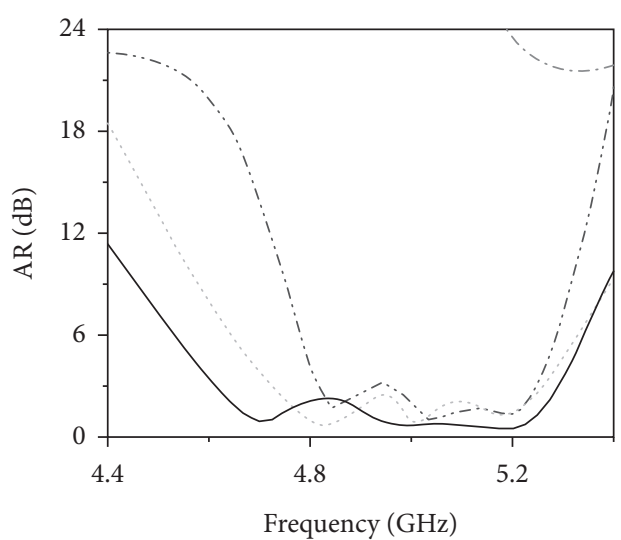

$\begin{array}{ll}\cdots \text { Ant. I } & \cdots-. \cdot \text { Ant. III } \\ -.- \text { Ant. II } & \end{array}$

(c)

FIGURE 2: Four antenna structures in the design process and corresponding $\left|S_{11}\right|$ curves and AR curves for different antennas, (a) $\left|S_{11}\right|$ curves, (b) AR curves, and (c) four antenna structures.

TABLE 1: Comparison of the designed antenna with previously reported antennas.

\begin{tabular}{|c|c|c|c|c|c|}
\hline $\begin{array}{l}\text { Ref. } \\
\text { antenna }\end{array}$ & Type & Antenna size $\left(\lambda_{0}^{3}\right)$ & $\begin{array}{c}-10 \mathrm{~dB} \\
\text { IBW (\%) }\end{array}$ & $\begin{array}{c}3 \mathrm{~dB} \\
\text { ARBW (\%) }\end{array}$ & $\begin{array}{l}\text { Peak gain } \\
\quad(\mathrm{dBi})\end{array}$ \\
\hline [11] & $\begin{array}{l}\text { Four cut-truncated square patches + sequentially rotated } \\
\text { series-parallel stub }\end{array}$ & $\begin{array}{c}1.55 \times 1.55 \times 0.024 \text { at } \\
5.6 \mathrm{GHz}\end{array}$ & 15.4 & 5.4 & 14.0 \\
\hline [12] & Four notched circular patches + a single-stage transition & $\begin{array}{c}1.16 \times 1.16 \times 0.013 \text { at } \\
2.5 \mathrm{GHz}\end{array}$ & 8 & 4.8 & 7.5 \\
\hline [14] & $\begin{array}{l}\text { Four cut-truncated square patches }+ \text { four strip lines }+ \text { SP } \\
\text { square loop }\end{array}$ & $\begin{array}{c}1.38 \times 1.38 \times 0.028 \text { at } \\
5.5 \mathrm{GHz}\end{array}$ & 18 & 12.7 & 12 \\
\hline [16] & $\begin{array}{c}\text { Four strips }+ \text { four rectangular patches }+ \text { four square } \\
\text { patches }+ \text { SP square loop }\end{array}$ & $\begin{array}{c}1.47 \times 1.47 \times 0.028 \text { at } \\
5.5 \mathrm{GHz}\end{array}$ & 15.8 & 11.8 & 12.5 \\
\hline [17] & $\begin{array}{l}\text { Four cut-truncated square patches }+ \text { four square patches }+ \text { SP } \\
\text { square loop }\end{array}$ & $\begin{array}{c}0.92 \times 0.92 \times 0.028 \text { at } \\
5.5 \mathrm{GHz}\end{array}$ & 19.5 & 12.9 & 9.8 \\
\hline [22] & $\begin{array}{c}\text { A parasitic L-shaped patch }+ \text { four parasitic square } \\
\text { patches }+ \text { SP square loop }\end{array}$ & $\begin{array}{c}0.80 \times 0.80 \times 0.076 \text { at } \\
5.6 \mathrm{GHz}\end{array}$ & 38 & 28.1 & 8.4 \\
\hline [23] & $\begin{array}{l}\text { Four L-shaped patches with L-shaped slots }+ \text { four square } \\
\text { patches }+ \text { a corner-truncated square patch }+ \text { SP square loop }\end{array}$ & $\begin{array}{l}0.95 \times 0.95 \times 0.12 \text { at } \\
5.6 \mathrm{GHz}\end{array}$ & 25.5 & 16.7 & 10.8 \\
\hline [24] & $\begin{array}{l}\text { Eight corner-truncated parasitic square patches }+ \text { SP square } \\
\text { loop }\end{array}$ & $\begin{array}{c}0.92 \times 0.92 \times 0.073 \text { at } \\
5.6 \mathrm{GHz}\end{array}$ & 33.6 & 19.4 & 10.2 \\
\hline Proposed & $\begin{array}{c}\text { Four rectangular patches }+ \text { Four L-shaped slots }+ \text { SP } \\
\text { square loop }\end{array}$ & $\begin{array}{c}1.03 \times 1.03 \times 0.028 \text { at } \\
5.6 \mathrm{GHz}\end{array}$ & 18.0 & 13.2 & 9.1 \\
\hline
\end{tabular}

$\lambda_{0}$ is the free space wavelength at the center frequency of the overlapped band.

2.3. Surface Current Analysis. To understand the underlying $\mathrm{CP}$ working principle, Figure 3 depicts the simulated surface current distributions of the proposed CP MSA with vector characteristics. The correspondingly continuous phases of $0^{\circ}$ and $90^{\circ}$ are also marked in Figure 3. Observed that the surface currents are orthogonal in $0^{\circ}$ and $90^{\circ}$, which 


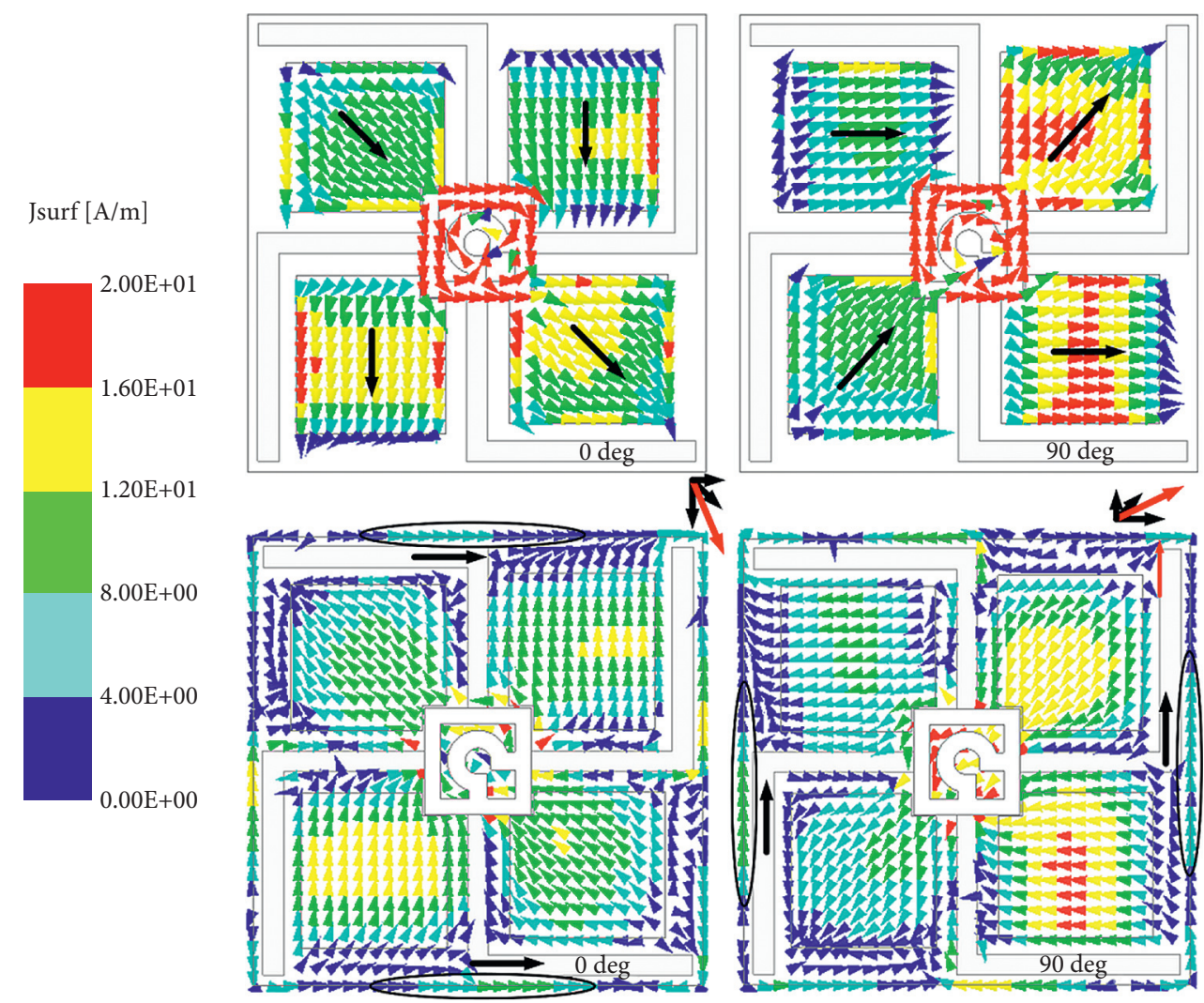

(a)

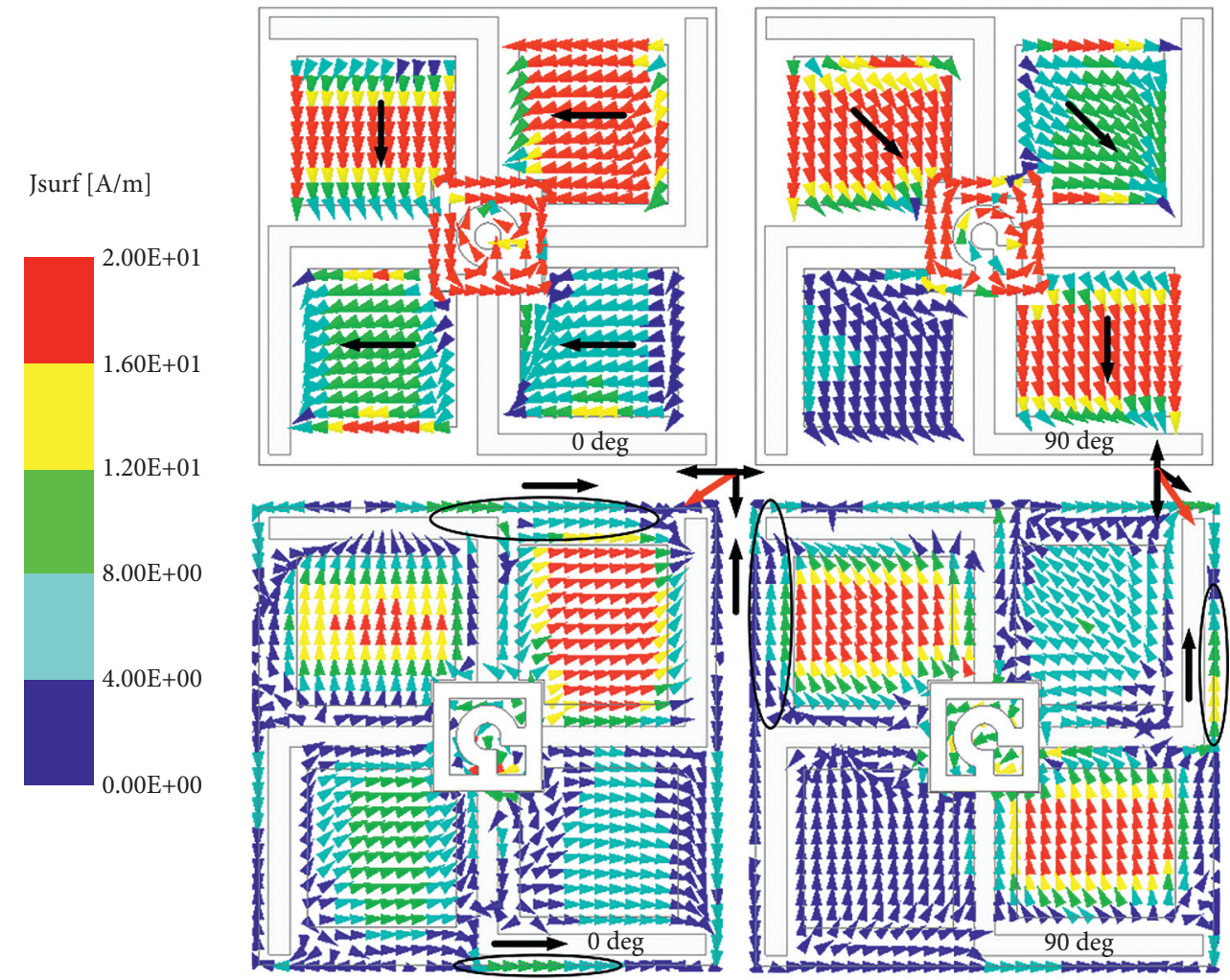

(b)

FIGURE 3: Simulated vector electric field distribution in the CP MSA and its corresponding principal planes with different phases of $0^{\circ}$ and $90^{\circ}$ at (a) $4.7 \mathrm{GHz}$ and (b) $5.2 \mathrm{GHz}$, respectively. 


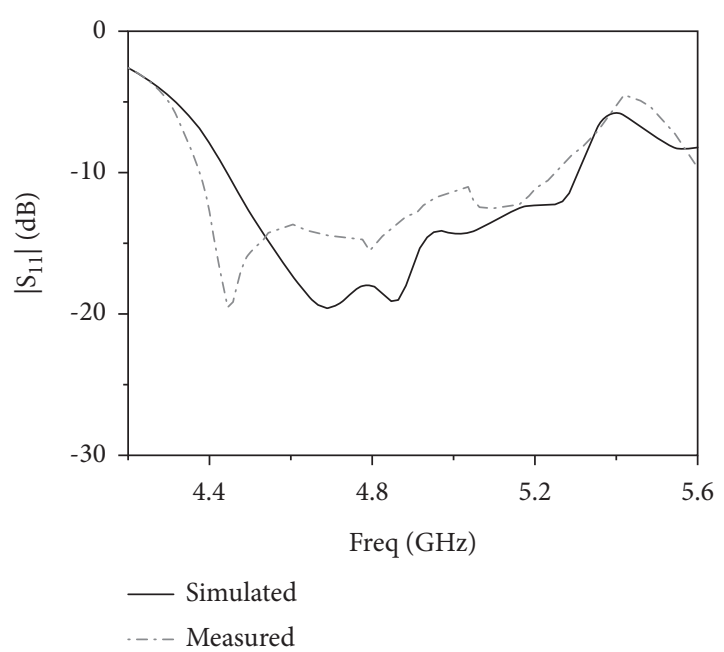

(a)

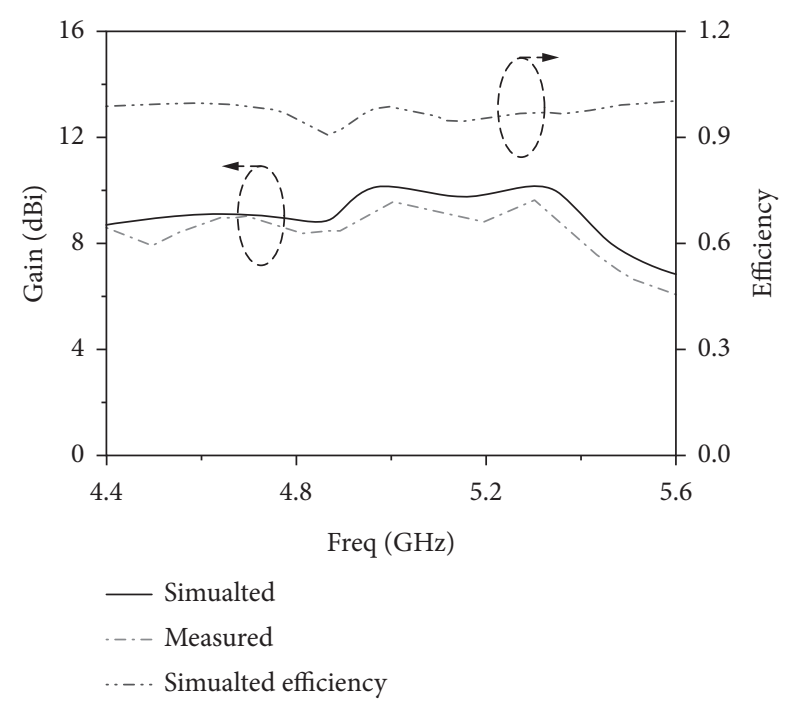

(c)

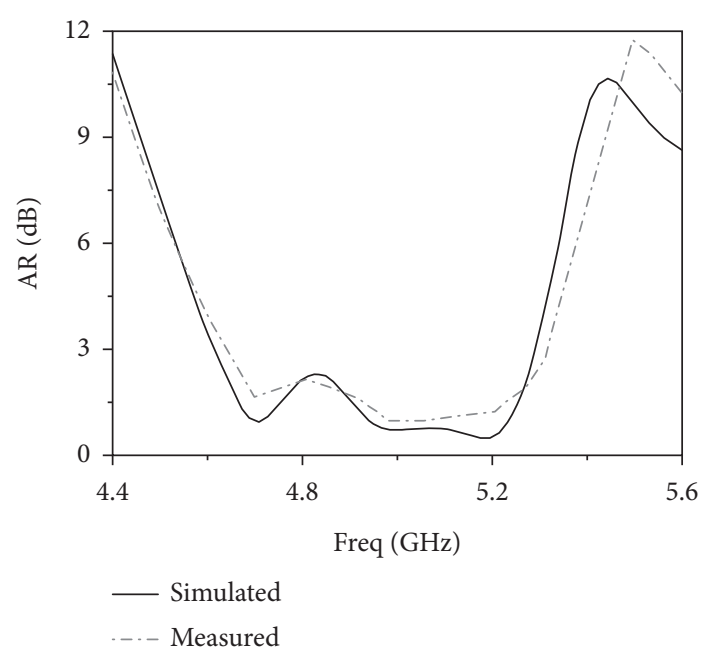

(b)

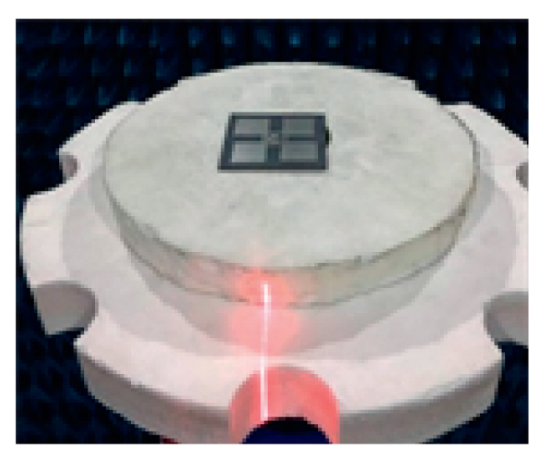

(d)

FIGURE 4: $\left|S_{11}\right|$, AR, gain, and radiation efficiency curves of simulated and tested results of antenna prototype and antenna photograph: (a) | $S_{11} \mid$ curves, (b) AR curves, (c) gain and efficiency curves, and (d) antenna photograph.

is a necessary condition for exciting $\mathrm{CP}$, the surface current is mainly distributed on the rectangular patch, with a small amount of distribution on edge of the $L$-shaped slot, whether at low frequency $(4.7 \mathrm{GHz})$ or high frequency $(5.2 \mathrm{GHz})$. Note that the surface currents on the rectangular patch and $L$-shaped slot with different phases $\left(0^{\circ}\right.$ and $\left.90^{\circ}\right)$ are orthogonal. The total surface current of the proposed CP MSA is the vector sum of the surface currents on the edge of $L$-shaped slots and rectangular patches. As shown in Figure 3, the total surface currents could rotate counterclockwise with varying phases $\left(0^{\circ}\right.$ and $\left.90^{\circ}\right)$ at $\mathrm{AR}$ resonance points $(4.7$ and $5.2 \mathrm{GHz}$ ). Thus, the proposed $\mathrm{CP}$ MSA radiates right-hand CP waves in the $+z$ direction. Additionally, according to the above analysis, we can conclude that the etched $L$-shaped slots introduce a new current flow path and make the ground plane participate in the radiation. Furthermore, the $\mathrm{CP}$ bandwidth of the proposed CP MSA can be improved.

\section{Experimental Results}

In this section, a simulated model of the proposed CP MSA was printed and tested to verify the rationality of the design. The $\left|S_{11}\right|$ values are tested by a vector network analyzer (VNA), while the AR, gain, and radiation pattern values are tested by the Satimo Starlab System. For comparison, Figures 4 and 5 depict the correspondingly simulated and measured results. Note that the measured $3 \mathrm{~dB} A R B W$ and $-10 \mathrm{~dB}$ IBW are $13.2 \%(4.98,4.65-5.31 \mathrm{GHz})$ and $18.0 \%$ $(4.815,4.38-5.25 \mathrm{GHz})$, whereas the simulated results are $13.7 \% \quad(4.95, \quad 4.61-5.29 \mathrm{GHz})$ and $17.6 \%$ (4.88, $4.45-5.31 \mathrm{GHz})$, respectively. Based on the simulated and measured results, the measured and simulated CP bandwidths are $12.1 \%(4.95,4.65-5.25 \mathrm{GHz})$ and $13.7 \% \quad(4.95$, $4.61-5.29 \mathrm{GHz})$. The simulated gains and radiation efficiencies and measurement environment photograph of antenna are shown in Figures 4(c) and 4(d), respectively. The 

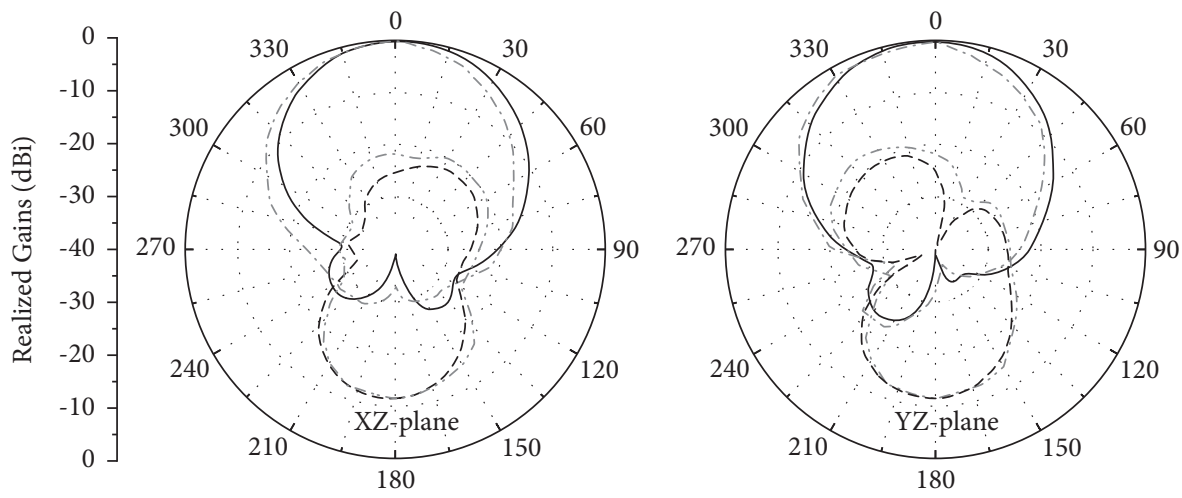

- - Simulated LHCP

- Simulated RHCP

.... Measured LHCP

-. - Measured RHCP

(a)
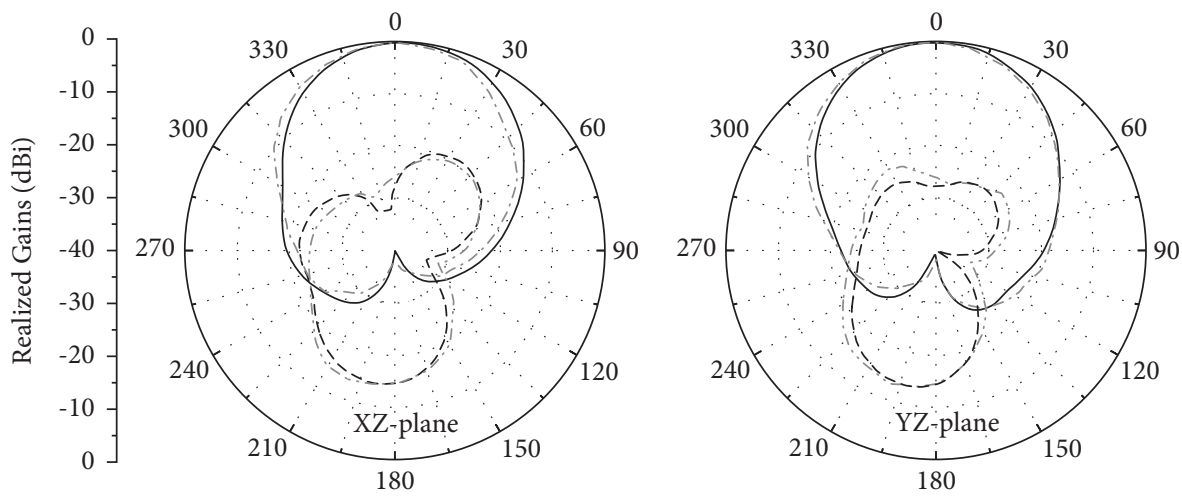

- - - Simulated LHCP

- Simulated RHCP

.... Measured LHCP

-. - Measured RHCP

(b)
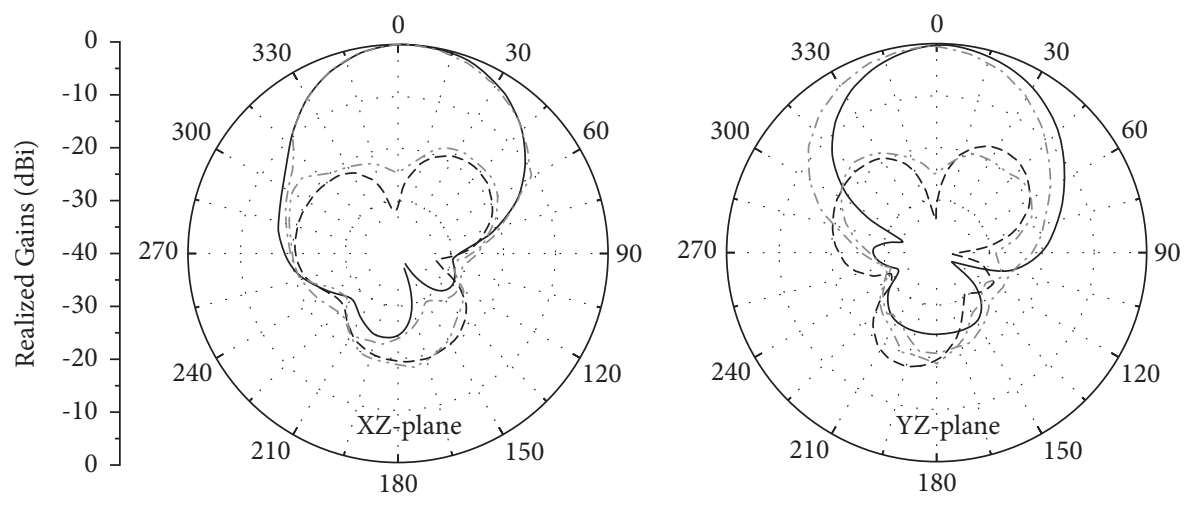

- - - Simulated LHCP

- Simulated RHCP

.... Measured LHCP

-. - Measured RHCP

(c)

FIGURE 5: Simulated and tested radiation patterns of the designed antenna at (a) $4.7 \mathrm{GHz}$, (b) $5.0 \mathrm{GHz}$, and (c) $5.2 \mathrm{GHz}$.

measured gains are smaller than the simulated gains at the entire frequency band due to the measurement errors. The simulated and measured peak gains are 10.2 and $9.1 \mathrm{dBi}$, and the simulated radiation efficiencies are greater than $90 \%$ within the CPBW. Additionally, Figure 5 depicts the normalized radiation patterns at $4.7,5.0$, and $5.2 \mathrm{GHz}$. The figure shows the simulated and measured left-hand $\mathrm{CP}$ waves are less than the right-hand $\mathrm{CP}$ parts by at least $20 \mathrm{~dB}$ in the yozand xoz-plane, which reveals that the proposed CP MSA could radiate right-hand $\mathrm{CP}$ waves. Because of the error in manufacturing and measured environment, minor differences between the tested and simulated values could be found. 


\section{Conclusion}

In this study, a compact wideband CP MSA with parasitic elements is designed. The proposed CP MSA consists of a square-loop SP feed network, four rotated rectangular patches, and four L-shaped slots embedded in the ground plane. The square-loop SP feed network is composed of a square loop and an arc-shaped strip, which could provide a $270^{\circ}$ phase difference. Four rotated rectangular patches are placed at the edge of the square-loop feeding configuration using a capacitively tightly coupled feeding method to stimulate a CP resonant. The bandwidth of CP MSA could be improved by combining CP modes produced by parasitic elements. After selecting these elements and tuning proper dimensions, the broad operating bandwidths of 4.38-5.25 GHz (18\%) for $\left|S_{11}\right|<-10 \mathrm{~dB}$ and $4.65-5.31 \mathrm{GHz}$ (13.2\%) for $\mathrm{AR}<3 \mathrm{~dB}$ could be realized. Hence, the proposed CP MSA has a potential application value in wireless communication.

\section{Data Availability}

The data used to support the findings of this study are available from the corresponding author upon request.

\section{Conflicts of Interest}

The authors declare that they have no conflicts of interest.

\section{Acknowledgments}

The research was funded by Guangzhou Basic and Applied Basic Research Foundation (no. 202102020883).

\section{References}

[1] C. Kumar, M. I. Pasha, and D. Guha, "Defected ground structure integrated microstrip array antenna for improved radiation properties," IEEE Antennas and Wireless Propagation Letters, vol. 16, pp. 310-312, 2017.

[2] W. Zhou, J. Liu, and Y. Long, "A broadband and high-gain planar complementary Yagi array antenna with circular polarization," IEEE Transactions on Antennas and Propagation, vol. 65, no. 3, pp. 1446-1451, 2017.

[3] E. Arnieri, L. Boccia, G. Amendola, and G. Di Massa, "A compact high gain antenna for small satellite applications," IEEE Transactions on Antennas and Propagation, vol. 55, no. 2, pp. 277-282, 2007.

[4] H. L. Chung, X. Qing, and Z. Ning, "Broadband circularly polarized stacked patch antenna for UHF RFID applications," in Proceedings of the IEEE Antennas and Propagation Society International Symposium, pp. 1189-1192, Honolulu, HI, USA, June 2007.

[5] H. Zhou and W. Hong, "Compact circularly polarized patch array antenna," IEEE Antennas and Wireless Propagation Letters, vol. 15, pp. 778-781, 2016.

[6] J. Shi, X. Wu, X. Qing, and Z. N. Chen, "An omnidirectional circularly polarized antenna array," IEEE Transactions on Antennas and Propagation, vol. 64, no. 2, pp. 574-581, 2016.

[7] A. B. Smolders, R. M. C. Mestrom, A. C. F. Reniers, and M. Geurts, "A shared aperture dual-frequency circularly polarized microstrip array antenna," IEEE Antennas and Wireless Propagation Letters, vol. 12, pp. 120-123, 2013.

[8] L. Bian and X. Q. Shi, "Wideband circularly-polarized serial rotated $2 \times 2$ circular patch antenna array," Microwave and Optical Technology Letters, vol. 49, no. 12, pp. 3122-3124, 2007.

[9] Y. Lu, D. G. Fang, and H. Wang, "A wideband circularly polarized $2 \times 2$ sequentially rotated patch antenna array," Microwave and Optical Technology Letters, vol. 49, no. 6, pp. 1405-1407, 2007.

[10] J.-W. Baik, T.-H. Lee, S. Pyo, S.-M. Han, J. Jeong, and Y.-S. Kim, "Broadband circularly polarized crossed dipole with parasitic loop resonators and its arrays," IEEE Transactions on Antennas and Propagation, vol. 59, no. 1, pp. 80-88, 2011.

[11] A. Chen, Y. Zhang, Z. Chen, and S. Cao, "A \$Ka\$ -band highgain circularly polarized microstrip antenna array," IEEE Antennas and Wireless Propagation Letters, vol. 9, no. 1, pp. 1115-1118, 2010.

[12] S.-K. Lin and Y.-C. Lin, "A compact sequential-phase feed using uniform transmission lines for circularly polarized sequential-rotation arrays," IEEE Transactions on Antennas and Propagation, vol. 59, no. 7, pp. 2721-2724, 2011.

[13] A. Rahardjo, S. Kitao, and M. Haneishi, "Circularly polarized planar antenna excited by cross-lot coupled coplanar wave guide feedline," in Proceedings of the International Symposium on Antennas Propagation Society, pp. 2220-2223, Seattle, WA, USA, June1994.

[14] C. Deng, Y. Li, Z. Zhang, and Z. Feng, "A wideband sequential-phase fed circularly polarized patch array," IEEE Transactions on Antennas and Propagation, vol. 62, no. 7, pp. 3890-3893, 2014.

[15] Y.-Qi Zhang, S.-T. Qin, X.-W. Wang, and F. Shang, "Novel single-fed broadband circularly polarized antenna for GNSS applications," International Journal of RF and Microwave Computer-Aided Engineering, vol. 28, no. 7, Article ID e21193, 2018.

[16] K. Ding, C. Gao, T. Yu, D. Qu, and B. Zhang, "Gain-improved broadband circularly polarized antenna array with parasitic patches," IEEE Antennas and Wireless Propagation Letters, vol. 16, no. 99, pp. 1468-1471, 2017.

[17] K. Ding, C. Gao, D. Qu, and Q. Yin, "Compact broadband circularly polarized antenna with parasitic patches," IEEE Transactions on Antennas and Propagation, vol. 65, no. 9, pp. 4854-4857, 2017.

[18] P. Nasimuddin, K. P. Esselle, and A. K. Verma, "Wideband high-gain circularly polarized stacked microstrip antennas with an optimized C-type feed and a short horn," IEEE Transactions on Antennas and Propagation, vol. 56, no. 2, pp. 578-581, 2008.

[19] Z. Wang, S. Fang, S. Fu, and S. Jia, "Single-fed broadband circularly polarized stacked patch antenna with horizontally meandered strip for universal UHF RFID applications," IEEE Transactions on Microwave Theory and Techniques, vol. 59, no. 4, pp. 1066-1073, 2011.

[20] W. Yang, J. Zhou, Z. Yu, and L. Li, "Single-fed low profile broadband circularly polarized stacked patch antenna," IEEE Transactions on Antennas and Propagation, vol. 62, no. 10, pp. 5406-5410, 2014.

[21] X. Chen, G. Fu, S.-X. Gong, Y.-L. Yan, and W. Zhao, "Circularly polarized stacked annular-ring microstrip antenna with integrated feeding network for UHF RFID readers," IEEE Antennas and Wireless Propagation Letters, vol. 9, no. 7, pp. $542-545,2010$. 
[22] W. W. Yang, W. J. Sun, W. Qin, J. X. Chen, and J. Y. Zhou, "Broadband circularly polarised stacked patch antenna with integrated dual-feeding network," IET Microwaves, Antennas \& Propagation, vol. 11, no. 12, pp. 1791-1795, 2017.

[23] W. Su, J. Li, and R.-H. Liu, “A compact double-layer wideband circularly polarized microstrip antenna with parasitic elements," International Journal of RF and Microwave Computer-Aided Engineering, vol. 31, no. 7, 2020.

[24] K. Ding, R. Hong, D. Guan, Li Liu, and Y. Wu, "Broadband circularly polarized stacked antenna with sequential-phase feed technique," IET Microwaves, Antennas \& Propagation, vol. 14, no. 1, pp. 1791-1795, 2020.

[25] L. Wang and Y.-F. En, "A wideband circularly polarized microstrip antenna with multiple modes," IEEE Open Journal of Antennas and Propagation, vol. 1, pp. 413-418, 2020. 